\title{
Microwave induced in-situ formation of SiC nanowires on SiCNO ceramic aerogels with excellent electromagnetic wave absorption performance
}

\author{
Keke YUAN ${ }^{a, \dagger}$, Daoyang HAN ${ }^{a, \dagger}$, Junfang LIANG $^{a}$, Wanyu ZHAO ${ }^{b}$, \\ Mingliang $\mathrm{LI}^{a,{ }^{*}}$, Biao $\mathrm{ZHAO}^{c}$, Wen $\mathrm{LIU}^{a}$, Hongxia LU${ }^{a}$, \\ Hailong $\mathrm{WANG}^{a}$, Hongliang $\mathrm{XU}^{a}$, Gang $\mathrm{SHAO}^{a,{ }^{*}}$, Rui ZHANG ${ }^{a, d}$ \\ ${ }^{a}$ School of Materials Science and Engineering, Zhengzhou University, Zhengzhou 450001, China \\ ${ }^{b}$ The 27th Research Institute of China Electronic Technology Group Corporation, Zhengzhou 450047, China \\ ${ }^{c}$ Henan Key Laboratory of Aeronautical Material and Application Technology, School of Materials \\ Science and Engineering, Zhengzhou University of Aeronautics, Zhengzhou 450046, China \\ ${ }^{d}$ School of Materials Science and Engineering, Luoyang Institute of \\ Science and Technology, Luoyang 471023, China
}

Received: April 29, 2021; Revised: June 14, 2021; Accepted: June 24, 2021

(C) The Author(s) 2021.

\begin{abstract}
Electromagnetic absorption (EMA) materials with light weight and harsh environmental robustness are highly desired and crucially important in the stealth of high-speed vehicles. However, meeting these two requirements is always a great challenge, which excluded the most attractive lightweight candidates, such as carbon-based materials. In this study, $\mathrm{SiC}_{\mathrm{nw}}$-reinforced $\mathrm{SiCNO}\left(\mathrm{SiC}_{\mathrm{nw}} /\right.$ $\mathrm{SiCNO}$ ) composite aerogels were fabricated through the in-situ growth of $\mathrm{SiC}_{\mathrm{nw}}$ in polymer-derived $\mathrm{SiCNO}$ ceramic aerogels by using catalyst-assisted microwave heating at ultra-low temperature and in short time. The phase composition, microstructure, and EMA property of the $\mathrm{SiC}_{\mathrm{nw}} / \mathrm{SiCNO}$ composite aerogels were systematically investigated. The results indicated that the morphology and phase composition of $\mathrm{SiC}_{\mathrm{nw}} / \mathrm{SiCNO}$ composite aerogels can be regulated easily by varying the microwave treatment temperature. The composite aerogels show excellent EMA property with minimum reflection loss of $-23.9 \mathrm{~dB} @ 13.8 \mathrm{GHz},-26.5 \mathrm{~dB} @ 10.9 \mathrm{GHz}$, and $-20.4 \mathrm{~dB} @ 14.5 \mathrm{GHz}$ and the corresponding effective bandwidth of $5.2 \mathrm{GHz}, 3.2 \mathrm{GHz}$, and $4.8 \mathrm{GHz}$ at $2.0 \mathrm{~mm}$ thickness for microwave treatment at $600{ }^{\circ} \mathrm{C}, 800{ }^{\circ} \mathrm{C}$, and $1000{ }^{\circ} \mathrm{C}$, respectively, which is much better than that of $\mathrm{SiCN}$ ceramic aerogels. The superior EMA performance is mainly attributed to the improved impedance matching, multireflection, multi-interfacial polarization, and micro current caused by migration of hopping electrons.
\end{abstract}

Keywords: polymer-derived $\mathrm{SiCNO}$ ceramic aerogel; $\mathrm{SiC}$ nanowires $\left(\mathrm{SiC}_{\mathrm{nw}}\right)$; microwave heating; electromagnetic absorption (EMA) performance

\footnotetext{
$\dagger$ Keke Yuan and Daoyang Han contributed equally to this work.

* Corresponding authors.

E-mail: M. Li, bright_de@zzu.edu.cn;

G.Shao,gang_shao@zzu.edu.cn
} 


\section{Introduction}

Recently, tremendous efforts have been devoted to developing excellent electromagnetic absorption (EMA) materials for electronic safety and defense stealth technology [1,2]. The ideal EMA materials are required with the properties of light weight, broad band, strong absorption, and thinness [3-5]. Owing to large density, narrow band width, and easy oxidation, traditional EMA materials, such as ferrite [6], magnetic metal powders [7], and carbon materials [8] cannot meet the absorption demands. To achieve good EMA properties, the materials should be composed of electrical insulating phase and an electric and/or dielectric loss phase for providing good impedance matching and EM attenuation ability, as well as multiple phases and multi-dimensional structures, to further improve the EMA properties by additional interfacial polarization and multi-reflection of microwaves.

Polymer-derived SiCN ceramics (PDC-SiCN) possess excellent thermal mechanical property and oxidation/ corrosion resistance [9-11], and owing to their easilytunable microstructure and composition [12], especially the carbon dangling-bonds in $\mathrm{SiCN}$ matrix $[13,14]$, the EMA property of PDC-SiCN is also excellent, such as $\mathrm{SiCN}$ [15] and SiBCN/graphene@ $\mathrm{Fe}_{3} \mathrm{O}_{4}$ [16]. These studies show excellent EMA abilities of PDCs due to their high dielectric and/or electric loss. However, the previous studies all focus on dense and/or low porosity bulky materials, meaning that the density needs to be further decreased to meet the requirement of "lightweight".

PDC aerogels synthesized in our previous work present ultralow density $\left(0.19 \mathrm{~g} / \mathrm{cm}^{3}\right)$ and excellent EMA properties, due to the multiple reflections of EM waves in $3 \mathrm{D}$ porous structures and interfacial polarization [17]. However, as the drawbacks of all kinds of ceramic aerogels, the PDC aerogels are also fragile. In order to improve the mechanical property of PDC aerogels, in-situ growth of $1 \mathrm{D} \mathrm{SiC}$ nanowires $\left(\mathrm{SiC}_{\mathrm{nw}}\right)$ in aerogels is proposed; moreover, it is beneficial to establish nano-heterogeneous interfaces for strengthening interface polarization, and improve the absorbing ability finally [18]. Usually, the growth of $\mathrm{SiC}_{\mathrm{nw}}$ or $\mathrm{SiC}$ whiskers in PDCs requires high temperature $\left(>1400{ }^{\circ} \mathrm{C}\right)$ and long time either with or without catalyst [19-21], and an effective way to produce 1D nanowires in PDCs is desirable.

The present work suggests a viable methodology for the fabrication of $\mathrm{SiC}_{\mathrm{nw}}$-reinforced $\mathrm{SiCNO}\left(\mathrm{SiC}_{\mathrm{nw}} / \mathrm{SiCNO}\right)$ composite aerogels using $\mathrm{Fe}$ as catalyst in the microwave heating process. The effects of microwave-treated temperature on microstructure evolution, dielectric and EMA properties of $\mathrm{SiC}_{\mathrm{nw}} / \mathrm{SiCNO}$ composite aerogels were investigated. The hierarchical architecture combined with $\mathrm{SiC}_{\mathrm{nw}}$ and $3 \mathrm{D}$ framework in aerogels was demonstrated to enhance the EMA. Meanwhile, the formation mechanisms of hierarchical architecture during the microwave heating and the microwave absorption mechanisms of $\mathrm{SiC}_{\mathrm{nw}} / \mathrm{SiCNO}$ composite aerogels were also discussed in details.

\section{Experimental procedure}

\section{1 Preparation of $\mathrm{SiC}_{\mathrm{nw}} / \mathrm{SiCNO}$ composite aerogels}

The PDC-SiCN aerogels were fabricated by combining the freeze-drying technique and PDC route similar to our previous study [17], specifically, which were obtained via pyrolysis in $\mathrm{N}_{2}$ atmosphere at $1000{ }^{\circ} \mathrm{C}$ and named as PDCA-SiCN. The prepared PDCA-SiCN was immersed in the acetone solution of ferrocene $\left(\mathrm{Fe}\left(\mathrm{C}_{5} \mathrm{H}_{5}\right)_{2}\right.$; Fengchuan Chemical Reagent Co., Ltd., China) with concentration of $5 \mathrm{mg} / \mathrm{mL}$ overnight and then dried naturally at room temperature. The ferrocene-modified PDCA-SiCN was heat treated in a microwave-material workstation (MobileLab, Tangshan Nano Source Microwave Thermal Instrument Manufacturing Co., Ltd., China) without any aided heaters at 600,800 , and $1000{ }^{\circ} \mathrm{C}$ for 10 min with a heating rate of $30{ }^{\circ} \mathrm{C} / \mathrm{min}$ under ultrahigh-purity $\mathrm{N}_{2}$ flow, which were named as mw-600, mw-800, and mw-1000, respectively.

\section{2 Characterization}

The crystalline structure of the aerogels was identified by X-ray diffraction (XRD; SmartLab, Rigaku Instrument Corp., Japan) with $\mathrm{Cu} \mathrm{K \alpha}$ radiation $(\lambda=1.5406 \AA)$. The morphology and element mapping of the aerogels were characterized by field emission scanning electron microscopy (FE-SEM; Quanta FEG 250, FEI Co. Ltd., USA) equipped with energy dispersive spectroscopy (EDS). Transmission electron microscopy (TEM) of the composite aerogels was performed using a TecnaiG2 F20 instrument (FEI Co., Ltd., the Netherlands) operating at an acceleration voltage of $200 \mathrm{kV}$. Laser Raman spectroscopy was attained by a MicroRaman spectrometer (LabRAM HR Evolution, Horiba Jobin 
Yvon Co., Ltd., Japan) with the $532 \mathrm{~nm}$ line of siliconsolid laser as the excitation source. The porosity of the aerogels was analyzed by $\mathrm{N}_{2}$ adsorption/desorption experiments (ASAP 2020 system, Micromeritics Instrument Corp., USA) at $77 \mathrm{~K}$. Specific surface area (SSA) and pore size distribution were calculated by employing the Brunauer-Emmett-Teller (BET) method and the Barrett-Joyner-Halenda (BJH) method, respectively. The relative complex permeability and permittivity of the sample-paraffin wax composite were determined by the coaxial line method through a vector network analyzer system at $2-18 \mathrm{GHz}$ range (Agilent N5234A, Agilent Technologies Inc., USA). The samples are mixed evenly with paraffin wax at $88 \%$ weight proportion, and the mixture is pressed into a coaxial ring with an inner diameter of $3 \mathrm{~mm}$ and an outer diameter of $7 \mathrm{~mm}$. According to the transmission line theory, the reflection loss (RL) of the composites can be calculated based on the measured data of relative complex permeability and permittivity.

\section{Results and discussion}

\section{1 Microstructure of $\mathrm{SiC}_{\mathrm{nw}} / \mathrm{SiCNO}$ composite aerogels}

Figure 1 shows the morphologies of as-prepared
PDC-SiCN aerogels and SiCN composite aerogels at different microwave heating temperatures. As is seen in Fig. 1(a), the PDC-SiCN aerogels possess 3D framework, the hierarchical pores range from mesopores to macropores, and the $\mathrm{SiCN}$ particles are smaller than $100 \mathrm{~nm}$. After ferrocene-modified PDC-SiCN aerogels were heat treated using microwave heating technology at $600{ }^{\circ} \mathrm{C}$, some short whiskers wrapped on the surfaces of SiCN ceramic matrix were observed (Fig. 1(b)). As the temperature increased to $800{ }^{\circ} \mathrm{C}$, as shown in Fig. 1(c), plenty of nanorods grew in void spaces of $\mathrm{SiCN}$ particles. Figure 1(d) shows the morphologies of $\mathrm{SiCN}$ aerogels after $1000{ }^{\circ} \mathrm{C}$ microwave heating, which displays that large numbers of nanowires generated upon $\mathrm{SiCN}$ matrix.

The composition of 1D nanostructure in PDC-SiCN aerogels was measured using EDS, and the typical EDS spectra obtained from the samples of mw-600, mw-800, and mw-1000 are presented in Fig. 2, which reveals that the $1 \mathrm{D}$ nanostructure consists of $\mathrm{Si}, \mathrm{C}$, and Fe elements and the distribution of Fe element is rather uniform; moreover, a small amount of $\mathrm{N}$ and $\mathrm{O}$ elements in $\mathrm{SiCN}$ matrix are also observed. Observations from high resolution image (Fig. 2) reveal that the $1 \mathrm{D}$ nanostructures exhibit a cylindrical shape with smooth surfaces. The average diameters are 25,35 , and $30 \mathrm{~nm}$
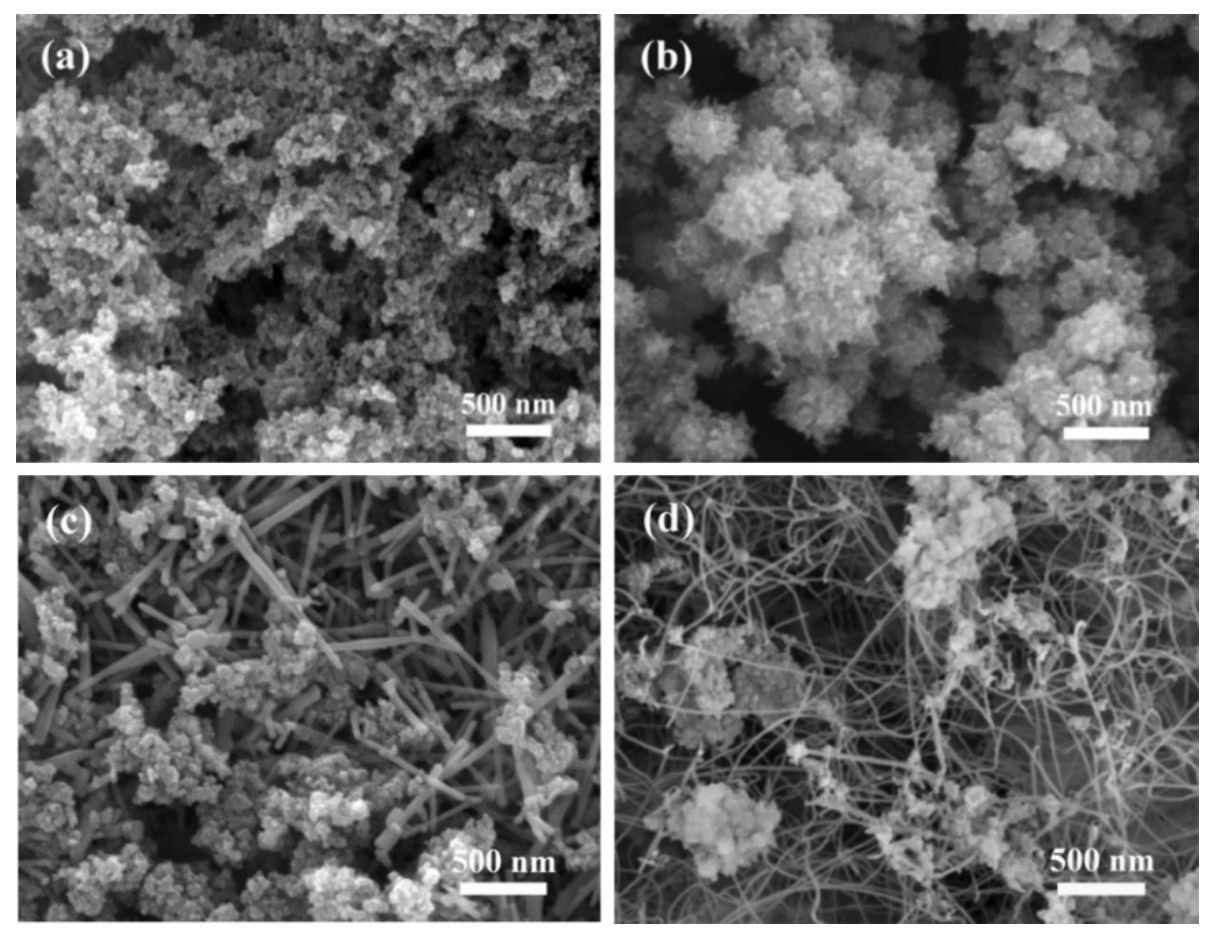

Fig. 1 SEM images of (a) SiCN aerogels and SiCN composite aerogels prepared by microwave heating at (b) $600{ }^{\circ} \mathrm{C}$, (c) $800{ }^{\circ} \mathrm{C}$, and (d) $1000{ }^{\circ} \mathrm{C}$. 
(a)
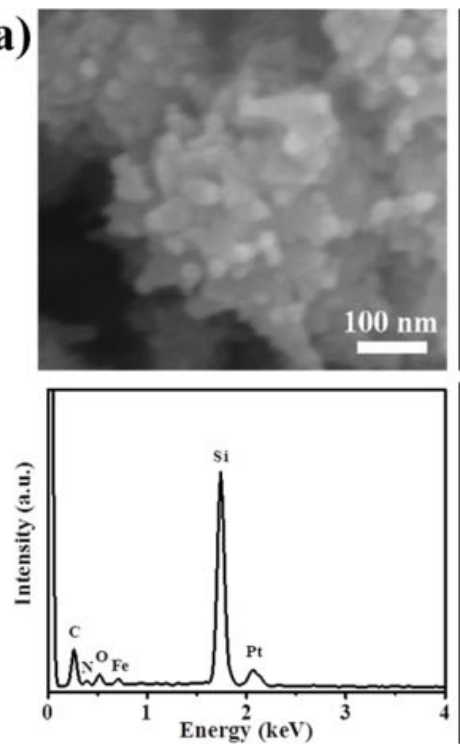

(b)
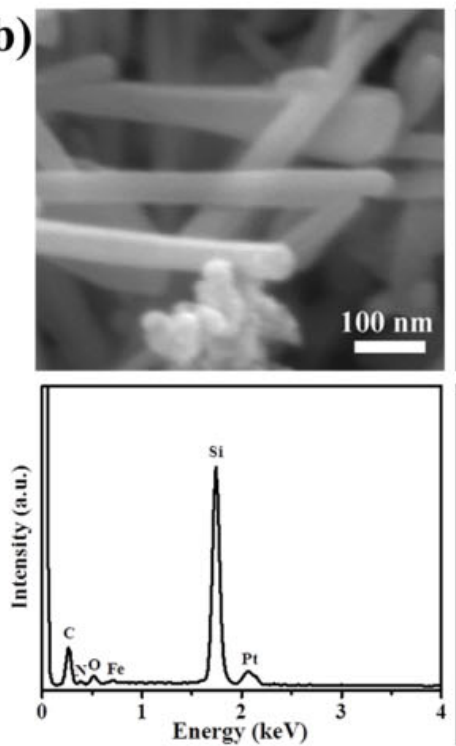

(c)
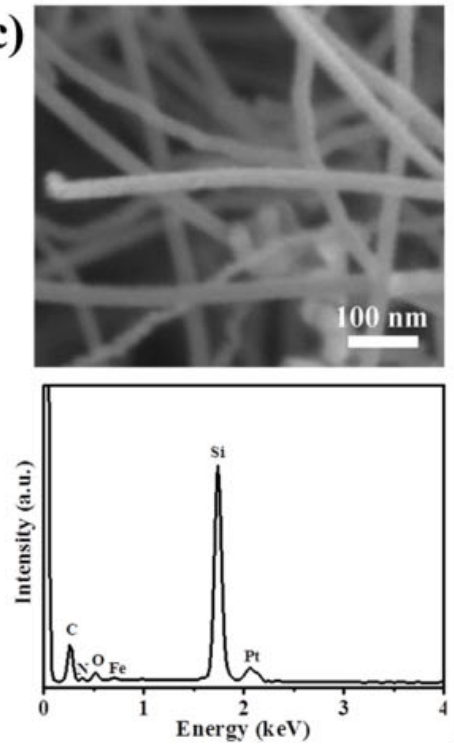

$\mathrm{Si}$

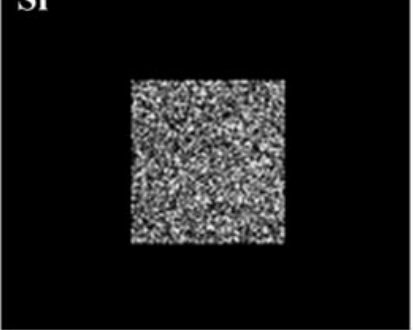

$\mathrm{Fe}$

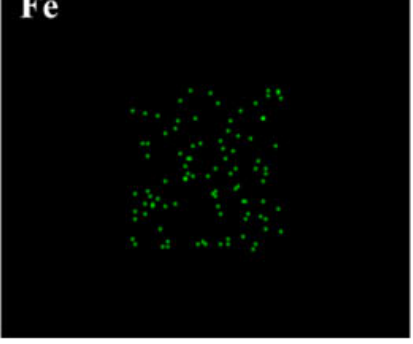

$\mathrm{Si}$

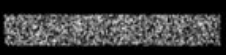
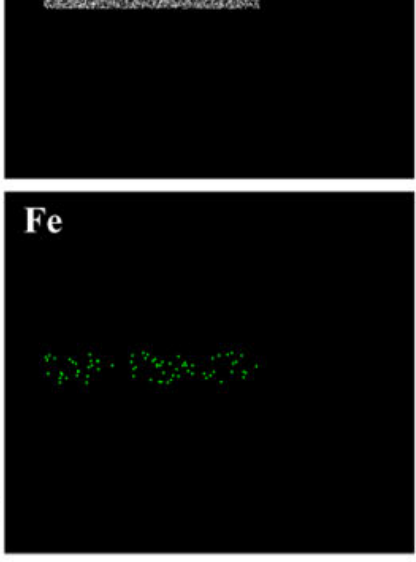

$\mathrm{Si}$

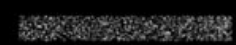
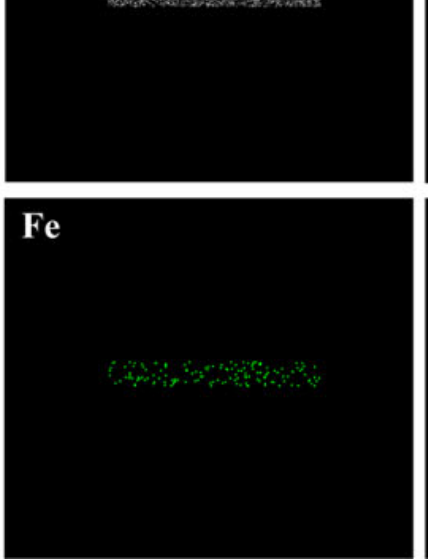
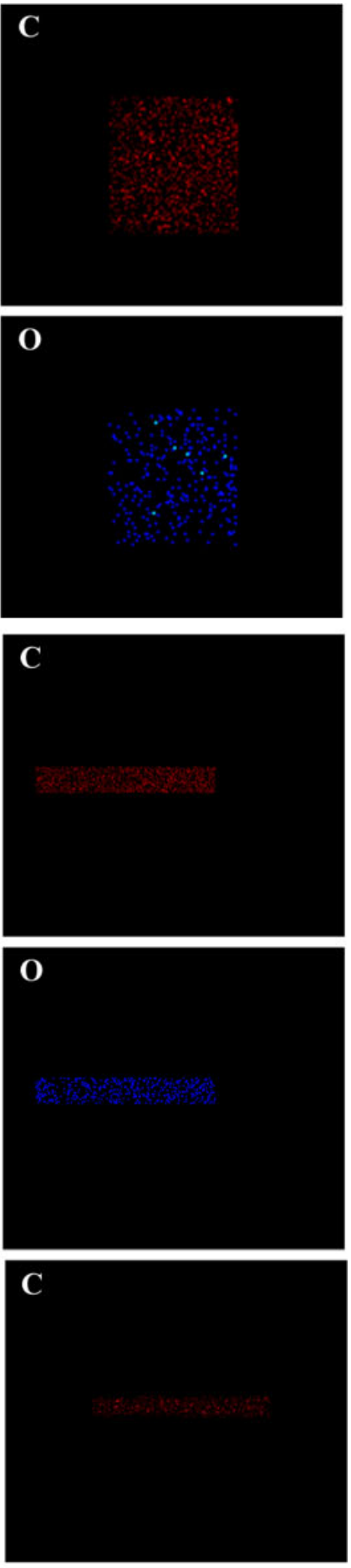

$\mathbf{O}$

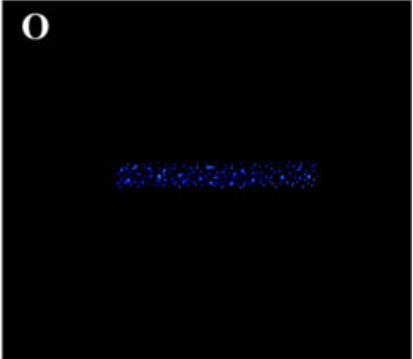

Fig. 2 EDS spectra of $\mathrm{SiCN}$ composite aerogels prepared by microwave heating at (a) $600{ }^{\circ} \mathrm{C}$, (b) $800{ }^{\circ} \mathrm{C}$, and (c) $1000{ }^{\circ} \mathrm{C}$. 
for the short whiskers, nanorods, and nanowires synthesized at 600,800 , and $1000{ }^{\circ} \mathrm{C}$, respectively. The diameter of the individual 1D nanostructure is uniform along its length. The average lengths of the short whiskers, nanorods, and nanowires are several tens of nanometers, several hundreds of nanometers, and few micrometers, respectively, which indicated that the size of 1D nanostructure can be tailored by varying the temperatures of microwave heating.

Figure 3 shows the XRD patterns of $\mathrm{SiCN}$ aerogels and $\mathrm{SiCN}$ composite aerogels. We can see that the $\mathrm{SiCN}$ aerogels pyrolyzed at $1000{ }^{\circ} \mathrm{C}$ remain amorphous; however, the ferrocene-modified SiCN aerogels after microwave heating were in crystalline state, and the diffraction peaks at $35.6^{\circ}, 41.4^{\circ}, 60.0^{\circ}, 71.8^{\circ}$, and $75.5^{\circ}$ belong to the (111), (200), (220), (311), and (222) planes of $\beta$-SiC (JCPDS 29-1129), respectively. The low intensity peak marked with S.F. is due to stacking faults $[22,23]$. The diffraction peaks of sample mw- 600 are broad in width and poor in intensity, suggesting low crystallization degree of $\mathrm{SiC}$. With the microwave heating temperature increasing, the diffraction peaks of $\beta$-SiC become sharper in width and stronger in intensity. The increased intensity indicates the increasing crystallization degrees of $\mathrm{SiC}$, and the decreased peak widths indicate the increase of the grain size. The peak at $26.1^{\circ}$ was indexed as the (002) plane of graphite carbon (JCPDS 41-1487), and the peak at $45.3^{\circ}$ was indexed as the (220) plane of $\mathrm{Fe}_{3} \mathrm{Si}$ (JCPDS 45-1207), which correspond to the results of EDS spectra. Considering the PDC-SiCN begins to crystallize at $1400{ }^{\circ} \mathrm{C}[24,25]$, the above results indicate that the crystallization of PDC-SiCN can be effectively enhanced by the ferrocene catalyst-assisted microwave heating at lower temperatures. The decrease of crystallization

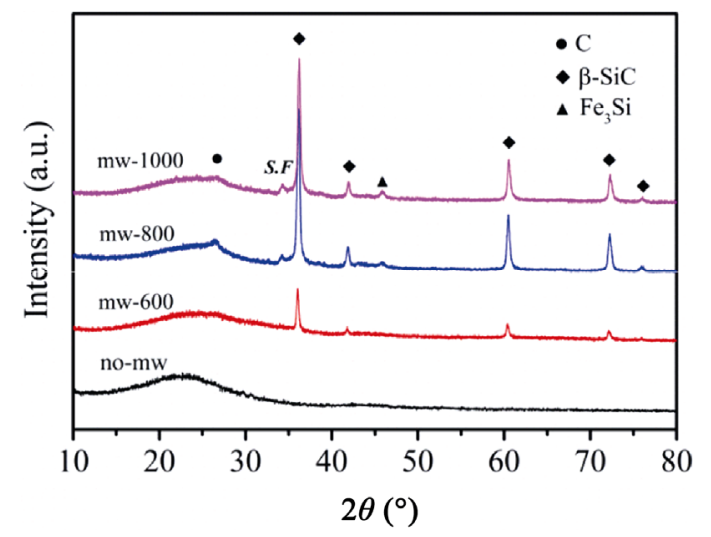

Fig. 3 XRD patterns of $\mathrm{SiCN}$ aerogels and $\mathrm{SiCN}$ composite aerogels. temperatures is due to the formation of liquid $\mathrm{Fe}-\mathrm{Si}-\mathrm{C}$ phase during microwave heating [26]. It is thought that the crystallization of $\mathrm{SiC}$ follows the solid-liquid-solid (SLS) mechanism when Fe exists in the system [27,28]. Precipitation occurs and gives rise to the $\mathrm{SiC}$ when the $\mathrm{Fe}-\mathrm{Si}-\mathrm{C}$ eutectic liquid alloys become saturated with $\mathrm{Si}$ and $\mathrm{C}$ atoms. Based on the above analysis, the 1D nanostructure in PDC-SiCN aerogels, according to their morphologies, is $\mathrm{SiC}$ whiskers, nanorods, or nanowires. Additionally, due to the oxygen distribution in SiCN matrix after ferrocene catalyst-assisted microwave heating, the SiCN composite aerogels after microwave heating were defined as $\mathrm{SiC}_{\mathrm{nw}}$-reinforced $\mathrm{SiCNO}$ $\left(\mathrm{SiC}_{\mathrm{nw}} / \mathrm{SiCNO}\right)$ composite aerogels.

Raman spectroscopy was employed to demonstrate the fine structure of carbon in PDCs. As shown in Fig. 4 , all spectra exhibit the most prominent features of the disorder-induced $\mathrm{D}$ band at $1350 \mathrm{~cm}^{-1}$ and the $\mathrm{G}$ band at $1600 \mathrm{~cm}^{-1}$ caused by in-plane bond stretching of $\mathrm{sp}^{2}$ carbons, suggesting the existence of free carbon in all samples. In addition, $\mathrm{SiC}$ band at about $800 \mathrm{~cm}^{-1}$ and $2 \mathrm{D}$ band at about $2700 \mathrm{~cm}^{-1}$ were presented in spectra of $\mathrm{SiC}_{\mathrm{nw}} / \mathrm{SiCNO}$ composite aerogels. The $2 \mathrm{D}$ band is the overtone of the D band, which is sensitive to the stacking orders of graphene layers along the $c$ axis [29]. In order to further analyze the features of free carbon, Raman spectra are fitted by the Lorentzian-BWF curve to determine the positions, widths, and $I_{\mathrm{D}} / I_{\mathrm{G}}$ intensity ratios (Table 1). Compared with the $\mathrm{SiCN}$ aerogels, the $\mathrm{D}$ band and $\mathrm{G}$ band of $\mathrm{SiC}_{\mathrm{nw}} / \mathrm{SiCNO}$ composite aerogels increased in intensity and decreased in width, suggesting the increasing graphitization degree of carbon. With the increase of microwave heating temperatures, the $\mathrm{D}$ band, $\mathrm{G}$ band, and 2D band become sharper, indicating the increasing crystallization

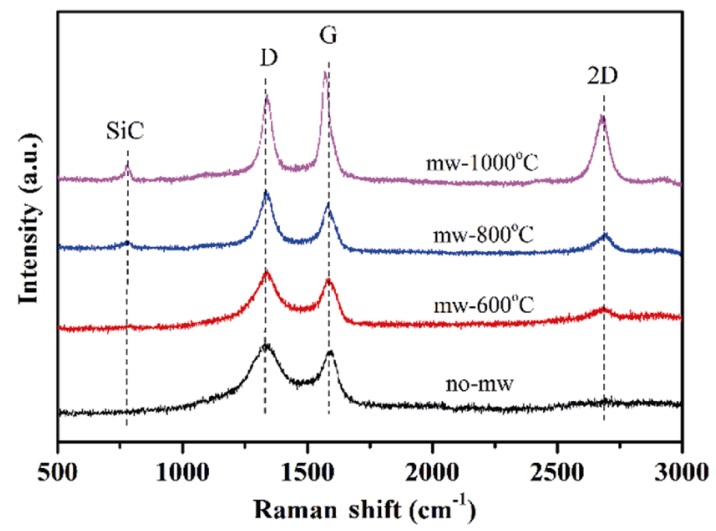

Fig. 4 Raman spectra of $\mathrm{SiCN}$ aerogels and $\mathrm{SiC}_{\mathrm{nw}} / \mathrm{SiCNO}$ composite aerogels. 
Table 1 Raman spectrum parameters of $\mathrm{SiCN}$ aerogels and $\mathrm{SiC}_{\mathrm{nw}} / \mathrm{SiCNO}$ composite aerogels

\begin{tabular}{crrrr}
\hline Sample & no-mw & mw-600 & mw-800 & mw-1000 \\
\hline D peak $\left(\mathrm{cm}^{-1}\right)$ & 1334.46 & 1336.17 & 1337.30 & 1339.38 \\
G peak $\left(\mathrm{cm}^{-1}\right)$ & 1593.96 & 1590.28 & 1586.69 & 1583.01 \\
D peak FWHM $\left(\mathrm{cm}^{-1}\right)$ & 132.13 & 108.42 & 66.42 & 43.13 \\
G peak FWHM $\left(\mathrm{cm}^{-1}\right)$ & 74.40 & 68.61 & 54.33 & 35.75 \\
$I_{\mathrm{D}} / I_{\mathrm{G}}$ & 1.46 & 1.26 & 1.15 & 0.89 \\
\hline
\end{tabular}

of carbon. Therefore, the microwave treatment and heating temperature both promoted the conversion of carbon from amorphous to graphite-like in $\mathrm{SiC}_{\mathrm{nw}} / \mathrm{SiCNO}$ composite aerogels.

Figure 5 shows the $\mathrm{N}_{2}$ sorption isotherms and pore size distributions of $\mathrm{SiCN}$ aerogels and $\mathrm{SiC}_{\mathrm{nw}} / \mathrm{SiCNO}$ composite aerogels. According to IUPAC classification, they are assigned to Type IV isotherms. The hysteresis loops could be further classified as H3, and the isotherm does not terminate at high pressure, indicating the presence of considerable fraction of mesopores and macropores. Hence, the PDC-SiCN aerogels consist of hierarchical porosity with a wide pore size dispersion in the range from 5 to $100 \mathrm{~nm}$ with a maximum close to $50 \mathrm{~nm}$ (Fig. 5(b)). It should be also mentioned that there is bimodal distribution in the pore diameter of 4 and $50 \mathrm{~nm}$ for the samples after microwave treatment. This can be explained that the smaller pore diameter is caused by the secondary SiC nanostructures and the larger pore diameter is caused by the primary $\mathrm{SiCN}$ frameworks. The details of pore size analysis are listed in Table 2. We can see that the PDC-SiCN aerogels have a surface area of $135 \mathrm{~m}^{2} / \mathrm{g}$ with average pore size of $18 \mathrm{~nm}$. The BET surface areas of the $\mathrm{SiC}_{\mathrm{nw}} / \mathrm{SiCNO}$ composite aerogels were 165,232 , and $173 \mathrm{~m}^{2} / \mathrm{g}$, which were higher than that of the $\mathrm{SiCN}$ aerogels.

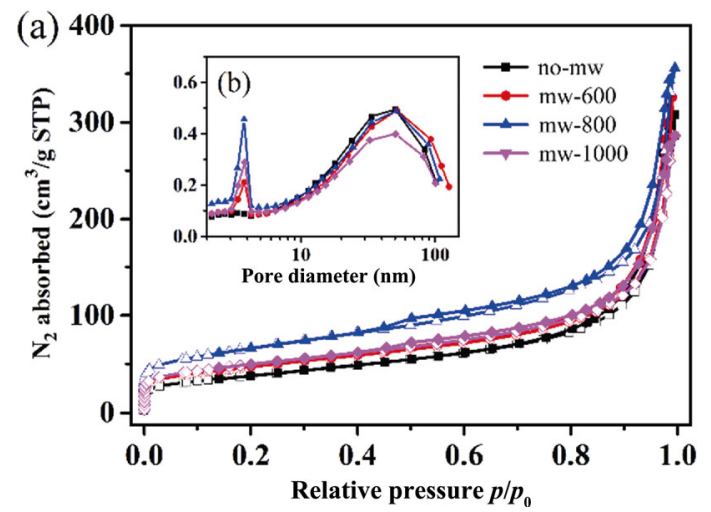

Fig. $5 \mathrm{~N}_{2}$ sorption isotherms and pore size distributions of $\mathrm{SiCN}$ aerogels and $\mathrm{SiC}_{\mathrm{nw}} / \mathrm{SiCNO}$ composite aerogels.
Table 2 Microstructural features of $\mathrm{SiCN}$ aerogels and $\mathrm{SiC}_{\mathrm{nw}} / \mathrm{SiCNO}$ composite aerogels

\begin{tabular}{cccc}
\hline Sample & $\begin{array}{c}\text { BET surface } \\
\text { area }\left(\mathrm{m}^{2} / \mathrm{g}\right)\end{array}$ & $\begin{array}{c}\text { Pore volume } \\
\left(\mathrm{cm}^{3} / \mathrm{g}\right)\end{array}$ & $\begin{array}{c}\text { Pore size } \\
(\mathrm{nm})\end{array}$ \\
\hline no-mw & 135 & 0.44 & 18 \\
mw-600 & 165 & 0.47 & 15 \\
mw-800 & 232 & 0.49 & 12 \\
mw-1000 & 173 & 0.40 & 12 \\
\hline
\end{tabular}

Contrarily, the average pore size of the $\mathrm{SiC}_{\mathrm{nw}} / \mathrm{SiCNO}$ composite aerogels was lower than that of the $\mathrm{SiCN}$ aerogel, which are 15, 12, and $12 \mathrm{~nm}$. As the temperature of microwave treatment increased up to $1000{ }^{\circ} \mathrm{C}$, the BET surface areas of the $\mathrm{SiC}_{\mathrm{nw}} / \mathrm{SiCNO}$ composite aerogels decrease, which is attribute to the formation of many 1D SiC nanostructures from $\mathrm{SiCN}$ matrix, leading to the collapse of partial frameworks and the increase of average pore size.

The TEM images of PDC-SiCN aerogels and $\mathrm{SiC}_{\mathrm{nw}} / \mathrm{SiCNO}$ composite aerogels are presented in Fig. 6. From Figs. 6(a)-6(c) we can see that the SiCN aerogels contain $\mathrm{SiCN}$ matrix and free carbon, and the selected area electric diffraction (SAED) inset in Fig. 6(a) shows a diffuse elastically scattered ring pattern, indicating the typical amorphous feature. As is seen from Figs. 6(e) and 6(f), the $\mathrm{SiC}$ nanowires with a diameter of about $30 \mathrm{~nm}$ can be observed clearly, associating with $\mathrm{SiCN}$ matrix and flexible graphene-like carbon. The interface spacing of $0.252 \mathrm{~nm}$ presented in TEM image (Fig. 6(d)) belongs to (111) plane of $\beta$-SiC. The corresponding SAED pattern indicates the existence of stacking faults, which originate from the environmental disturbances. The diffraction spots and rings also belong to the diffractions of $\mathrm{SiC}$.

The synthesis mechanism of $\mathrm{SiC}_{\mathrm{nw}} / \mathrm{SiCNO}$ composite aerogels occurred in high-energy microwave irradiation was discussed in detail, and the schematic is shown in Fig. 7. In the process of microwave treatment, free carbon within $\mathrm{SiCN}$ aerogels possess strong microwave absorbing ability, which can achieve selective and effective heating by the coupled thermal effect [30,31]. Firstly, under the action of microwave alternating electric field, the $\pi$ electrons of free carbon can move in the local state to form current; moreover, the $\pi$ electrons induced by microwave alternating electric field cannot be synchronized with the rapidly changes of electric field, so the electromagnetic energy will be converted into thermal energy, realizing the microwave heating. Then, ferrocenes loaded on the surfaces of 

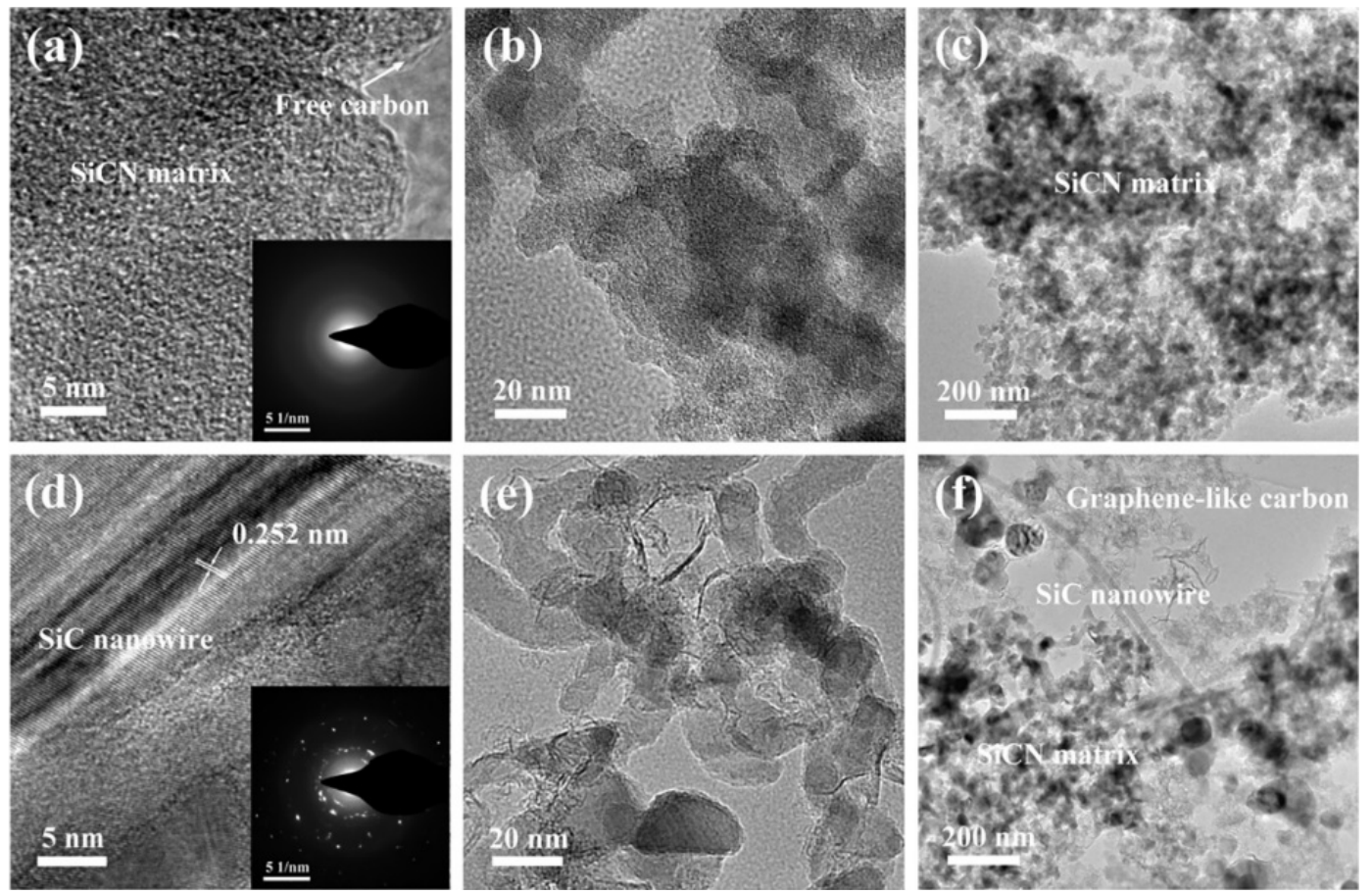

Fig. 6 TEM and SAED images of $(\mathrm{a}-\mathrm{c}) \mathrm{SiCN}$ aerogels and $(\mathrm{d}-\mathrm{f}) \mathrm{SiC}_{\mathrm{nw}} / \mathrm{SiCNO}$ composite aerogels prepared by microwave heating at $1000{ }^{\circ} \mathrm{C}$.

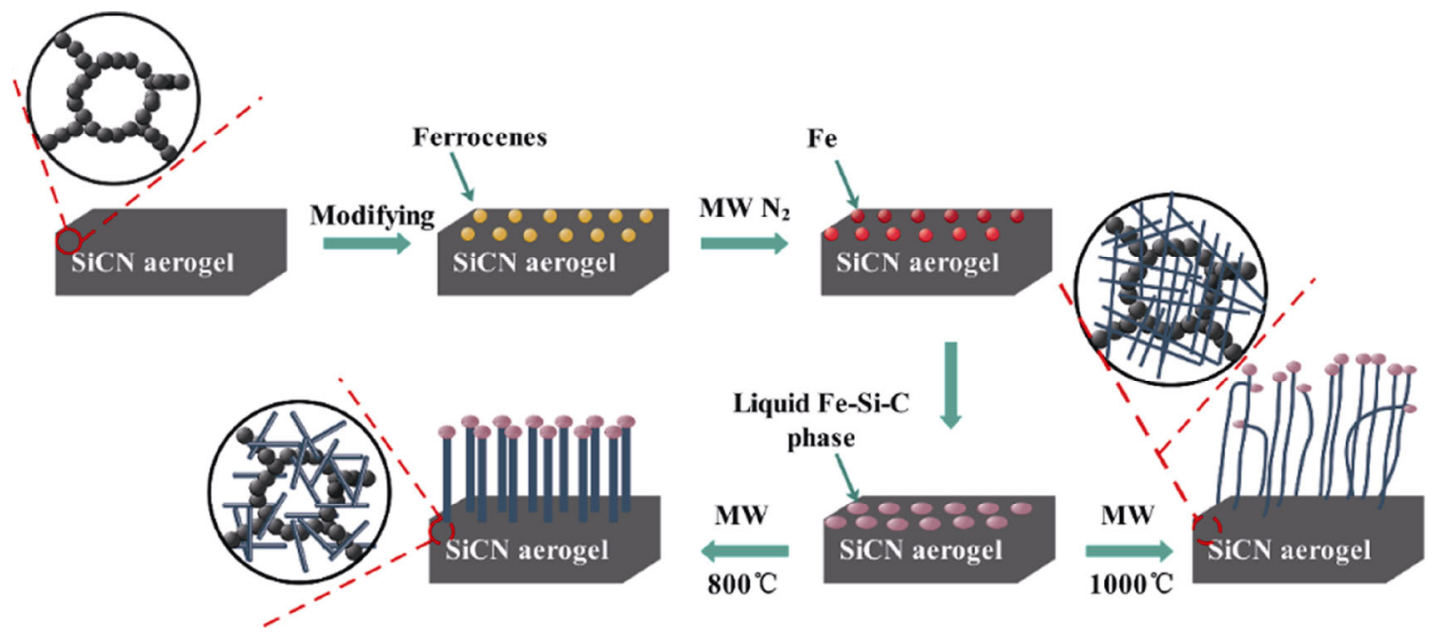

Fig. 7 Formation mechanism of $1 \mathrm{D} \mathrm{SiC}$ in $\mathrm{SiC}_{\mathrm{nw}} / \mathrm{SiCNO}$ composite aerogels.

SiCN aerogels begun to thermally decompose at about $200{ }^{\circ} \mathrm{C}$ by the heat from microwave absorbing of free carbons. The thermal decomposition products of ferrocenes were Fe nanoclusters and cyclopentadienyl, which are used as catalyst and partial carbon source, respectively. Under the Fe catalyst-assisted microwave heating, $\mathrm{Si}$ and $\mathrm{C}$ atoms were separated out to form $\mathrm{SiC}$ nucleation on the surfaces of $\mathrm{SiCN}$ matrix in the early stage; subsequently, 1D SiC nanostructures were grown on the surfaces or void spaces of SiCN matrix via an SLS mechanism [27]. The 3D porous structure of SiCN aerogels can provide sufficient space for the growth of $\mathrm{SiC}$ nanostructures, which can act as dielectric loss phases and interact with the microwave, further promoting the growth of $1 \mathrm{D} \mathrm{SiC} \mathrm{nanostructures.}$

\section{2 Microwave absorption property of $\mathrm{SiC}_{\mathrm{nw}} / \mathrm{SiCNO}$ composite aerogels}

The relative complex permittivity $\left(\varepsilon_{\mathrm{r}}=\varepsilon^{\prime}-\mathrm{j} \varepsilon^{\prime \prime}\right)$, permeability $\left(\mu_{\mathrm{r}}=\mu^{\prime}-\mathrm{j} \mu^{\prime \prime}\right)$, dielectric loss tangent, and magnetic loss tangent of $\mathrm{SiCN}$ aerogels and $\mathrm{SiC}_{\mathrm{nw}} / \mathrm{SiCNO}$ composite aerogels are presented in Fig. 8. It was 

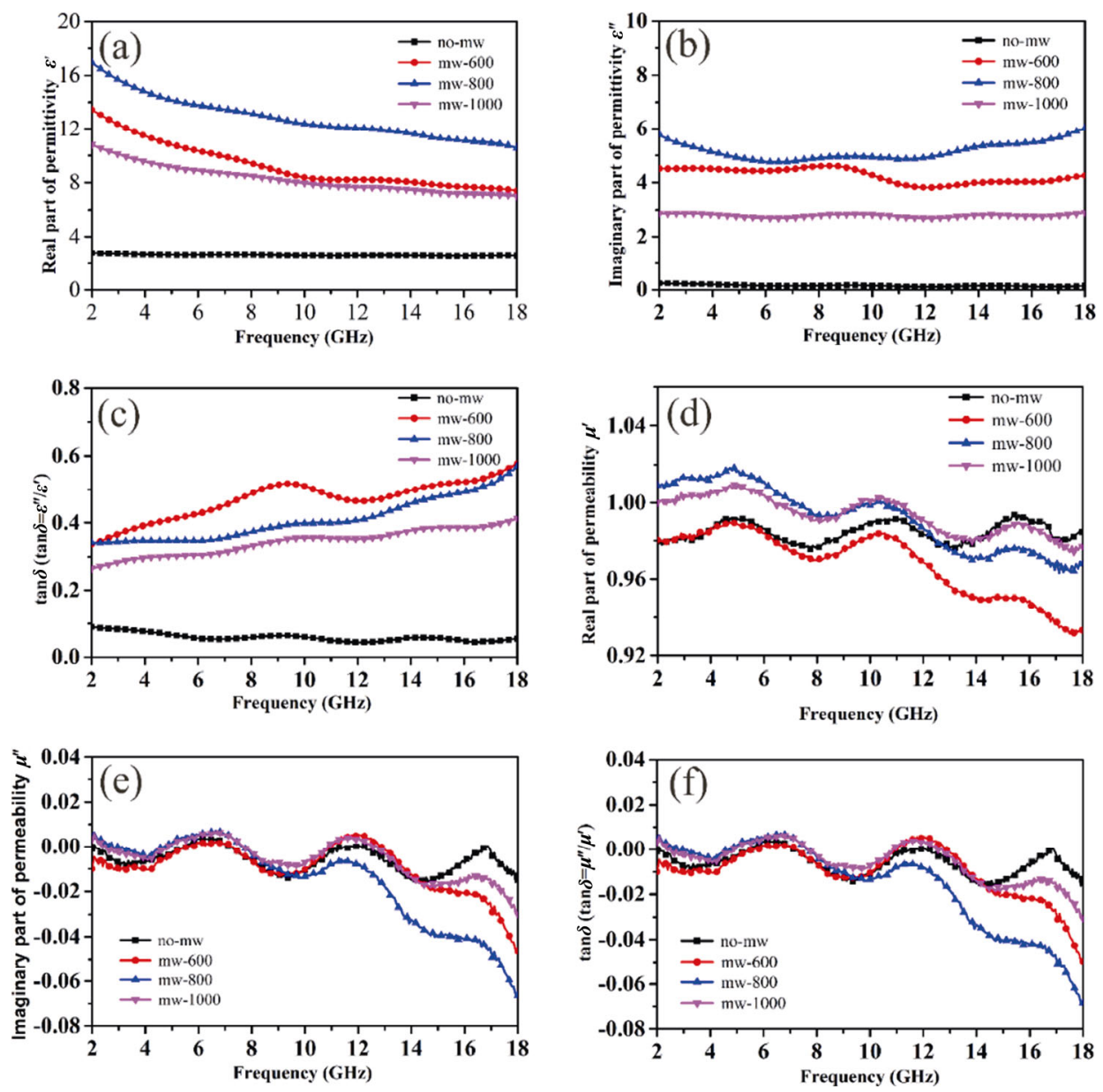

Fig. 8 (a, b) permittivity, (c) dielectric loss tangent, (d, e) permeability, and (f) magnetic loss tangent of SiCN aerogels and $\mathrm{SiC}_{\mathrm{nw}} / \mathrm{SiCNO}$ composite aerogels.

found that, in comparison to the $\mathrm{SiCN}$ aerogels, the real $\left(\varepsilon^{\prime}\right)$ and imaginary $\left(\varepsilon^{\prime \prime}\right)$ parts of complex permittivity, as well as the dielectric loss tangent $\left(\tan \delta_{\varepsilon}=\varepsilon^{\prime \prime} / \varepsilon^{\prime}\right)$ of $\mathrm{SiCn}_{\mathrm{w}} / \mathrm{SiCNO}$ composite aerogels obviously increased. It is well-known that $\varepsilon^{\prime}$ represents the storage capability of electric energy and $\varepsilon^{\prime \prime}$ represents the loss capability of electric energy, which are the key parameters for the characterization of dielectric property and predicting their EMA property. The significant changes in permittivity are mainly attributed to the $1 \mathrm{D} \mathrm{SiC}$ nanostructures and graphite-like carbon, which improved the interfacial polarization. Owing to the enhanced electric conductivity resulted from the graphitization of free carbon through $\mathrm{sp}^{3}$ to $\mathrm{sp}^{2}$ transition by microwave treatment, the dielectric loss increased with the microwave heating temperatures [17]. Therefore, the $\varepsilon^{\prime}$ and $\varepsilon^{\prime \prime}$ of $\mathrm{SiC}_{\mathrm{nw}} / \mathrm{SiCNO}$ composite aerogels can be effectively tailored by microwave treatment. However, the enhanced oxidation at $1000{ }^{\circ} \mathrm{C}$ resulted in the $\varepsilon^{\prime}$ and $\varepsilon^{\prime \prime}$ of the $\mathrm{SiC}_{\mathrm{nw}} / \mathrm{SiCNO}$ composite aerogels microwave-treated at $1000{ }^{\circ} \mathrm{C}$ lower than that of the other samples microwave-treated at 600 and $800{ }^{\circ} \mathrm{C}$. The variations of real $\left(\mu^{\prime}\right)$ and imaginary $\left(\mu^{\prime \prime}\right)$ parts of complex permeability, as well as the magnetic loss tangent $\left(\tan \delta_{\mu}=\mu^{\prime \prime} / \mu^{\prime}\right)$ of $\mathrm{SiC}_{\mathrm{nw}} / \mathrm{SiCNO}$ composite aerogels are smaller due to the trace generation of $\mathrm{Fe}_{3} \mathrm{Si}$, indicating minor magnetic loss contributions.

Figure 9 shows the reflection loss (RL) of $\mathrm{SiCN}$ aerogels and $\mathrm{SiC}_{\mathrm{nw}} / \mathrm{SiCNO}$ composite aerogels with 88 $\mathrm{wt} \%$ paraffin wax. The RL can be calculated according to Eqs. (1) and (2) based on the measured $\varepsilon_{\mathrm{r}}$ and $\mu_{\mathrm{r}}$ $[32,33]$ :

$$
\begin{gathered}
\mathrm{RL}=20 \log \left|\left(Z_{\text {in }}-Z_{0}\right) /\left(Z_{\text {in }}+Z_{0}\right)\right| \\
Z_{\text {in }}=Z_{0} \sqrt{\mu_{\mathrm{r}} / \varepsilon_{\mathrm{r}}} \tanh \left[\mathrm{j}\left(\frac{2 \pi f d}{c}\right) \sqrt{\mu_{\mathrm{r}} \varepsilon_{\mathrm{r}}}\right]
\end{gathered}
$$

where $Z_{0}$ is the impedance of free space, $Z_{\text {in }}$ is the input characteristic impedance, $\varepsilon_{\mathrm{r}}$ is the complex permittivity, $\mu_{\mathrm{r}}$ is the complex permeability, $f$ is the frequency, $c$ is the velocity of light, and $d$ is the thickness of materials. 

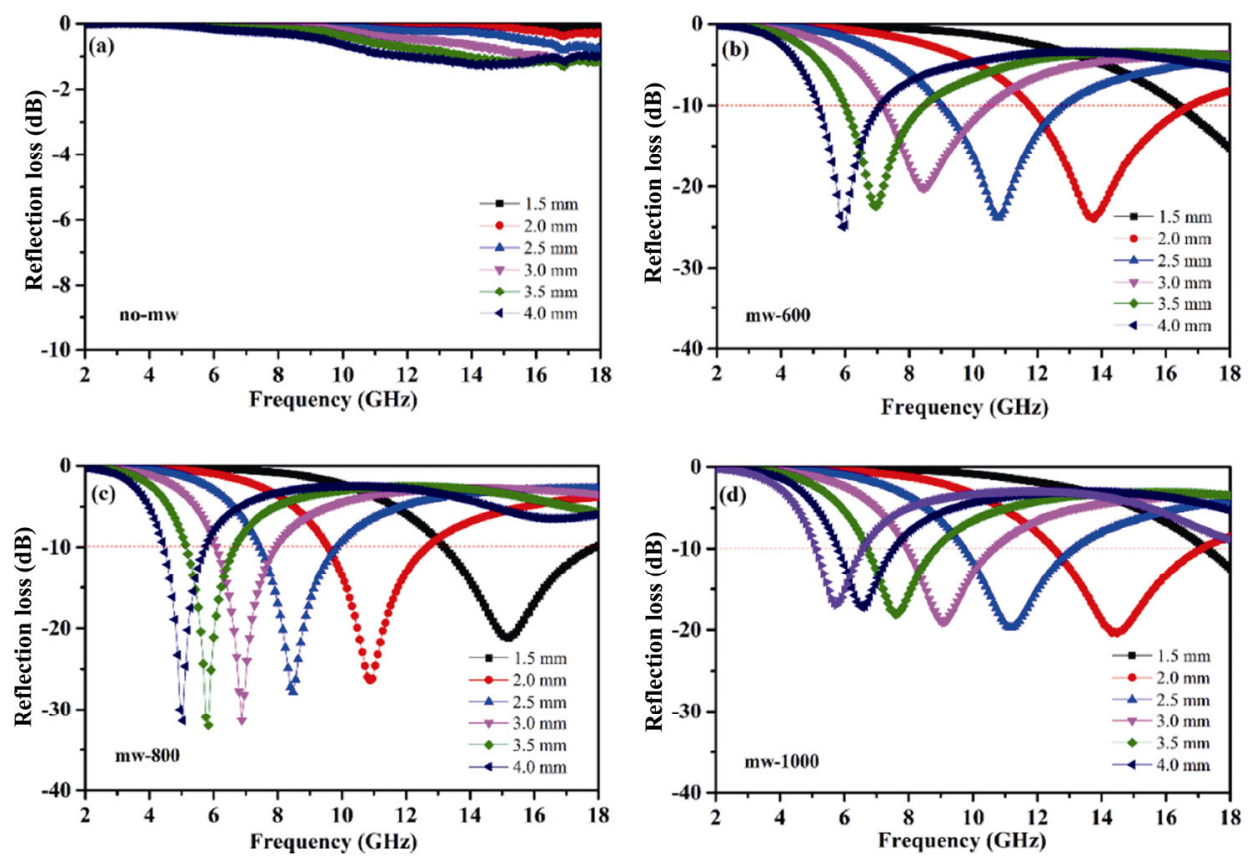

Fig. $9 \mathrm{RL}$ of (a) $\mathrm{SiCN}$ aerogels and $\mathrm{SiC}_{\mathrm{nw}} / \mathrm{SiCNO}$ composite aerogels prepared by microwave heating at (b) $600{ }^{\circ} \mathrm{C}$, (c) $800{ }^{\circ} \mathrm{C}$, and (d) $1000{ }^{\circ} \mathrm{C}$.

As shown in Fig. 9, it was found that the EMA property of $\mathrm{SiC}_{\mathrm{nw}} / \mathrm{SiCNO}$ composite aerogels after microwave heating was significantly higher than the $\mathrm{SiCN}$ aerogels. The minimum RL of mw-600, mw-800, and mw-1000 are $-23.9 \mathrm{~dB} @ 13.8 \mathrm{GHz},-26.5 \mathrm{~dB}$ @ $10.9 \mathrm{GHz}$, and $-20.4 \mathrm{~dB} @ 14.5 \mathrm{GHz}$ with the effective bandwidth of $5.2 \mathrm{GHz}, 3.2 \mathrm{GHz}$, and $4.8 \mathrm{GHz}$ at 2.0 $\mathrm{mm}$ thickness, respectively. Moreover, the minimum $\mathrm{RL}$ of mw- 800 can reach to $-31.9 \mathrm{~dB}$ at $3.0 \mathrm{~mm}$ thickness. The heterogeneous structure in $\mathrm{SiC}_{\mathrm{nw}} / \mathrm{SiCNO}$ composite aerogels can cause multiple scattering and interface polarization, which is conducive to enhance the dielectric loss and improve the EMA properties [34].

According to Debye theory, the dielectric loss consists of polarization loss and conductivity loss. The Debye relaxation equations are as follows $[35,36]$ :

$$
\begin{gathered}
\left(\varepsilon^{\prime}-\frac{\varepsilon_{\mathrm{s}}+\varepsilon_{\infty}}{2}\right)^{2}+\left(\varepsilon^{\prime \prime}\right)^{2}=\left(\frac{\varepsilon_{\mathrm{s}}-\varepsilon_{\infty}}{2}\right)^{2} \\
\varepsilon^{\prime}=\varepsilon_{\infty}+\frac{\varepsilon_{\mathrm{s}}-\varepsilon_{\infty}}{1+\omega^{2} \tau^{2}} \\
\varepsilon^{\prime \prime}=\frac{\varepsilon_{\mathrm{s}}-\varepsilon_{\infty}}{1+\omega^{2} \tau^{2}} \omega \tau+\frac{\sigma}{\omega \varepsilon_{0}}
\end{gathered}
$$

where $\varepsilon_{\mathrm{s}}$ is the static permittivity and $\varepsilon_{\infty}$ is the permittivity at infinite frequency. Obeying these equations, $\varepsilon^{\prime}$ and $\varepsilon^{\prime \prime}$ may form a semicircular curve called Cole-Cole semicircle. Each semicircle corresponds to one Debye relaxation process [37]. In order to clarify the origin of the relaxation processes, the plots of $\varepsilon^{\prime}$ versus $\varepsilon^{\prime \prime}$ of $\mathrm{SiCN}$ aerogels and $\mathrm{SiC}_{\mathrm{nw}} / \mathrm{SiCNO}$ composite aerogels were curved and shown in Fig. 10. It can be seen that there are some multi-dielectric relaxation processes in $\mathrm{SiCN}$ aerogels; however, compared with $\mathrm{SiCN}$ aerogels, the composite aerogels possess more additional semicircles, and the widths of semicircles are also larger, indicating that the presence of $1 \mathrm{D} \mathrm{SiC}$ nanostructures increases the number of relaxation processes and improves the intensity of the Debye relaxation processes. This behavior may be related to the charge transfer process occurring at the interfaces between $\mathrm{SiC}$ nanostructures and amorphous $\mathrm{SiCN}$ matrix. In addition, it should be noticed that there is also hopping migration between neighboring graphite-like carbon in the composite aerogels. The improved dielectric relaxation processes are also reflected in the tangent loss of $\mathrm{SiC}_{\mathrm{nw}} / \mathrm{SiCNO}$ composite aerogels and $\mathrm{SiCN}$ aerogels, as shown in Fig. 8(c). It can be found that the tangent loss of composite aerogels is higher than that of the $\mathrm{SiCN}$ aerogels over 2-18 GHz.

The schematic illustration of the microwave absorption mechanism in $\mathrm{SiC}_{\mathrm{nw}} / \mathrm{SiCNO}$ composite aerogels was shown in Fig. 11. The superior EMA properties of the composite aerogels are mainly attributed to the improved impedance matching due to the "antenna 

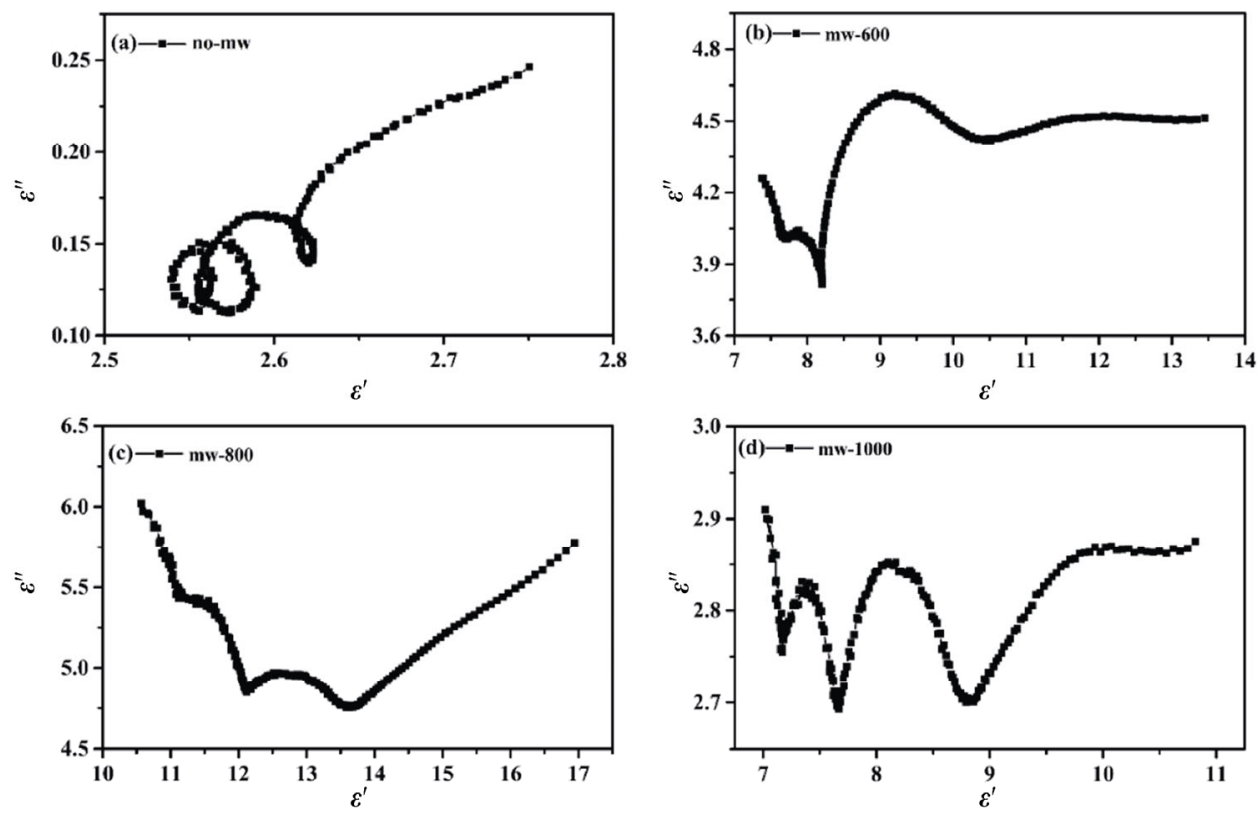

Fig. 10 Cole-Cole plots of (a) $\mathrm{SiCN}$ aerogels and $\mathrm{SiC}_{\mathrm{nw}} / \mathrm{SiCNO}$ composite aerogels prepared by microwave heating at (b) $600{ }^{\circ} \mathrm{C}$, (c) $800{ }^{\circ} \mathrm{C}$, and (d) $1000{ }^{\circ} \mathrm{C}$.

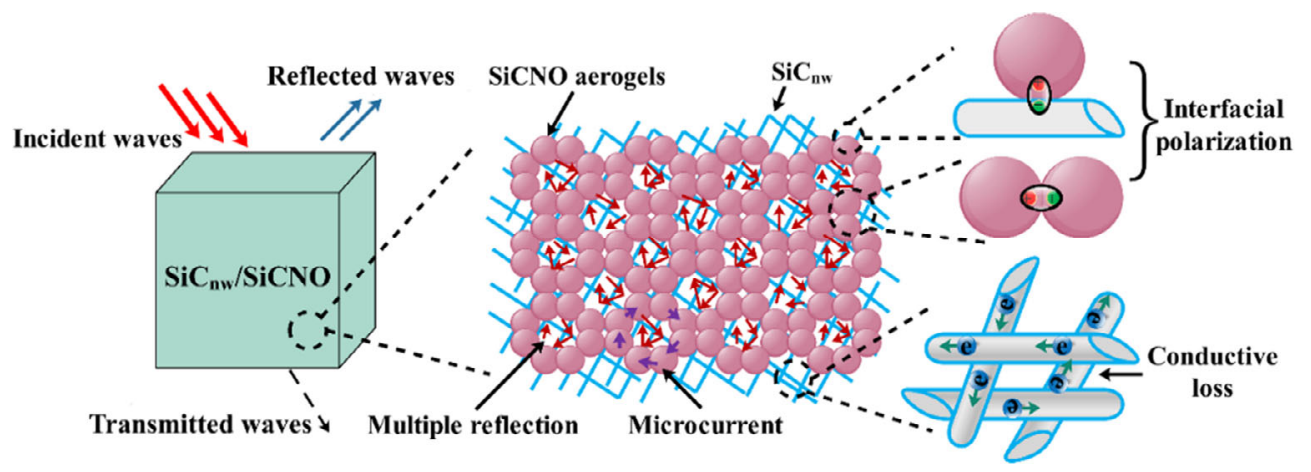

Fig. 11 Schematic illustration of the microwave absorption mechanism in $\mathrm{SiC}_{\mathrm{nw}} / \mathrm{SiCNO}$ composite aerogels.

effect" caused by $1 \mathrm{D} \mathrm{SiC}_{\mathrm{nw}}$ and proper electric conductivity, as well as the EM attenuation ability resulted from multi-interfacial polarization (free carbon, $\mathrm{SiCNO}$, and $\left.\mathrm{SiC}_{\mathrm{nw}}\right)$, multi-reflection, and micro current caused by migration of hopping electrons.

\section{Conclusions}

In summary, 1D SiC nanostructures were grown in-situ on the surfaces or void spaces in PDC-SiCN aerogels by catalyst-assisted microwave heating approach at ultra-low temperature. The formation process of $1 \mathrm{D}$ $\mathrm{SiC}$ nanostructures is ascribed to the SLS mechanism and the microwave couple effect. The minimum RL of $\mathrm{SiC}_{\mathrm{nw}} / \mathrm{SiCNO}$ composite aerogels (mw-600, mw-800, and mw-1000) are -23.9 dB@13.8 GHz, -26.5 dB
@ $10.9 \mathrm{GHz}$, and $-20.4 \mathrm{~dB} @ 14.5 \mathrm{GHz}$ with the effective bandwidth of $5.2 \mathrm{GHz}, 3.2 \mathrm{GHz}$, and $4.8 \mathrm{GHz}$ at $2.0 \mathrm{~mm}$ thickness, respectively. Experimental results and the theoretical simulation indicate that the enhanced EMA property of $\mathrm{SiC}_{\mathrm{nw}} / \mathrm{SiCNO}$ composite aerogels is attributed to the special structural characteristics, the improved impedance matching, interfacial polarization, multi-reflection, and micro current caused by migration of hopping electrons. In conclusion, this study provides an effective modification approach to improve the EMA property of PDC-SiCN aerogels, and the $\mathrm{SiC}_{\mathrm{nw}} / \mathrm{SiCNO}$ composite aerogels could be considered as a promising candidate in light-weight EMA materials.

\section{Acknowledgements}

The authors appreciate the financial support from the 
National Natural Science Foundation of China (Nos. U1904180 and 52072344), Excellent Young Scientists Fund of Henan Province (No. 202300410369), Henan Province University Innovation Talents Support Program (No. 21HASTIT001), and China Postdoctoral Science Foundation (No. 2021M692897).

\section{References}

[1] Yan DX, Pang H, Li B, et al. Structured reduced graphene oxide/polymer composites for ultra-efficient electromagnetic interference shielding. Adv Funct Mater 2015, 25: 559-566.

[2] Zhang WM, Zhao B, Xiang HM, et al. One-step synthesis and electromagnetic absorption properties of high entropy rare earth hexaborides $\left(\mathrm{HE} \mathrm{REB}{ }_{6}\right)$ and high entropy rare earth hexaborides/borates $\left(\mathrm{HE} \mathrm{REB} 6 \mathrm{HE} \mathrm{REBO}_{3}\right)$ composite powders. J Adv Ceram 2021, 10: 62-77.

[3] Duan WY, Yin XW, Li Q, et al. A review of absorption properties in silicon-based polymer derived ceramics. J Eur Ceram Soc 2016, 36: 3681-3689.

[4] Ye XL, Chen ZF, Ai SF, et al. Porous SiC/melaminederived carbon foam frameworks with excellent electromagnetic wave absorbing capacity. $J$ Adv Ceram 2019, 8: 479-488.

[5] Zhang YH, Si HX, Liu SC, et al. Facile synthesis of BN/Ni nanocomposites for effective regulation of microwave absorption performance. J Alloys Compd 2021, 850: 156680.

[6] Du YC, Liu WW, Qiang R, et al. Shell thickness-dependent microwave absorption of core-shell $\mathrm{Fe}_{3} \mathrm{O}_{4} @ \mathrm{C}$ composites. ACS Appl Mater Interfaces 2014, 6: 12997-13006.

[7] Shi XL, Cao MS, Yuan J, et al. Dual nonlinear dielectric resonance and nesting microwave absorption peaks of hollow cobalt nanochains composites with negative permeability. Appl Phys Lett 2009, 95: 163108.

[8] Jiang ZY, Si HX, Chen X, et al. Simultaneous enhancement of impedance matching and the absorption behavior of BN/RGO nanocomposites for efficiency microwave absorption. Compos Commun 2020, 22: 100503.

[9] Seo D, Jung S, Lombardo SJ, et al. Fabrication and electrical properties of polymer-derived ceramic (PDC) thin films for high-temperature heat flux sensors. Sens Actuat A: Phys 2011, 165: 250-255.

[10] Sun ZL, Zhou Y, Jia DC, et al. Mechanical and thermal physical properties of amorphous $\mathrm{SiCN}(\mathrm{O})$ ceramic bulks prepared by hot-press sintering. Mater Lett 2012, 72: 57-59.

[11] Zhao R, Shao G, Cao YJ, et al. Temperature sensor made of polymer-derived ceramics for high-temperature applications. Sens Actuat A: Phys 2014, 219: 58-64.

[12] Li Q, Yin XW, Duan WY, et al. Electrical, dielectric and microwave-absorption properties of polymer derived $\mathrm{SiC}$ ceramics in X band. J Alloys Compd 2013, 565: 66-72.
[13] Liu XF, Zhang LT, Yin XW, et al. The microstructure of $\mathrm{SiCN}$ ceramics and their excellent electromagnetic wave absorbing properties. Ceram Int 2015, 41: 11372-11378.

[14] Zhou W, Long L, Xiao P, et al. Silicon carbide nano-fibers in situ grown on carbon fibers for enhanced microwave absorption properties. Ceram Int 2017, 43: 5628-5634.

[15] Li Q, Yin XW, Duan WY, et al. Improved dielectric properties of PDCs-SiCN by in situ fabricated nano-structured carbons. J Eur Ceram Soc 2017, 37: 1243-1251.

[16] Luo C, Jiao T, Gu J, et al. Graphene shield by SiBCN ceramic: A promising high-temperature electromagnetic wave-absorbing material with oxidation resistance. ACS Appl Mater Interfaces 2018, 10: 39307-39318.

[17] Zhao WY, Shao G, Jiang MJ, et al. Ultralight polymer-derived ceramic aerogels with wide bandwidth and effective electromagnetic absorption properties. $J$ Eur Ceram Soc 2017, 37: 3973-3980.

[18] Song Y, Yin FX, Zhang CW, et al. Three-dimensional ordered mesoporous carbon spheres modified with ultrafine zinc oxide nanoparticles for enhanced microwave absorption properties. Nano Micro Lett 2021, 13: 1-16.

[19] Niu FX, Wang YX, Fu SL, et al. Ferrocene-assisted growth of $\mathrm{SiC}$ whiskers with hexagonal cross-section from a preceramic polymer. Ceram Int 2017, 43: 12983-12987.

[20] Yang K, Fox JT. In-situ growth of silicon carbide nanowire (SCNW) matrices from solid precursors. Ceram Int 2019, 45: 2922-2931.

[21] Adam M, Vakifahmetoglu C, Colombo $\mathrm{P}$, et al. Polysiloxane-derived ceramics containing nanowires with catalytically active tips. J Am Ceram Soc 2014, 97: 959-966.

[22] Pujar VV, Cawley JD. Effect of stacking faults on the X-ray diffraction profiles of $\beta$-SiC powders. J Am Ceram Soc 1995, 78: 774-782.

[23] Zhang HY, Xu YJ, Zhou JG, et al. Stacking fault and unoccupied densities of state dependence of electromagnetic wave absorption in SiC nanowires. J Mater Chem C 2015, 3: $4416-4423$.

[24] Song CQ, Yin XW, Han MK, et al. Three-dimensional reduced graphene oxide foam modified with $\mathrm{ZnO}$ nanowires for enhanced microwave absorption properties. Carbon 2017, 116: 50-58.

[25] Hou Y, Cheng LF, Zhang YN, et al. Electrospinning of $\mathrm{Fe} / \mathrm{SiC}$ hybrid fibers for highly efficient microwave absorption. ACS Appl Mater Interfaces 2017, 9: 7265-7271.

[26] Yang WY, Miao HZ, Xie ZP, et al. Synthesis of silicon carbide nanorods by catalyst-assisted pyrolysis of polymeric precursor. Chem Phys Lett 2004, 383: 441-444.

[27] Hauser R, Francis A, Theismann R, et al. Processing and magnetic properties of metal-containing $\mathrm{SiCN}$ ceramic micro- and nano-composites. J Mater Sci 2008, 43: 4042-4049.

[28] Li JH, Zhang YL, Fu YQ, et al. A simple and efficient route to synthesize hafnium carbide nanowires by catalytic 
pyrolysis of a polymer precursor. Ceram Int 2018, 44: 13335-13340.

[29] Lu MM, Cao WQ, Shi HL, et al. Multi-wall carbon nanotubes decorated with $\mathrm{ZnO}$ nanocrystals: Mild solution-process synthesis and highly efficient microwave absorption properties at elevated temperature. $J$ Mater Chem A 2014, 2: 10540-10547.

[30] Zhao WY, Li J, Fan BB, et al. Microwave synthesis of chain-like zircona nanofibers through carbon-induced self-assembly growth. Front Mater Sci 2017, 11: 353-357.

[31] Song BZ, Zhao B, Fan L, et al. Investigation on heating behavior during the preparation of $\mathrm{SiC}$ crystals by microwave sintering. Int J Appl Ceram Technol 2017, 14: 880-888.

[32] Chen $\mathrm{YH}$, Huang $\mathrm{ZH}$, Lu MM, et al. $3 \mathrm{D} \mathrm{Fe}_{3} \mathrm{O}_{4}$ nanocrystals decorating carbon nanotubes to tune electromagnetic properties and enhance microwave absorption capacity. $J$ Mater Chem A 2015, 3: 12621-12625.

[33] Wang L, Xing HL, Gao ST, et al. Porous flower-like $\mathrm{NiO} @$ graphene composites with superior microwave absorption properties. J Mater Chem C 2017, 5: 2005-2014.

[34] Zhang CW, Peng Y, Song Y, et al. Periodic three-dimensional nitrogen-doped mesoporous carbon spheres embedded with $\mathrm{Co} / \mathrm{Co}_{3} \mathrm{O}_{4}$ nanoparticles toward microwave absorption. ACS Appl Mater Interfaces 2020, 12: 24102-24111.
[35] He JZ, Wang XX, Zhang YL, et al. Small magnetic nanoparticles decorating reduced graphene oxides to tune the electromagnetic attenuation capacity. J Mater Chem C 2016, 4: 7130-7140.

[36] Zhao B, Liu JW, Guo XQ, et al. Hierarchical porous $\mathrm{Ni@boehmite/nickel} \mathrm{aluminum} \mathrm{oxide} \mathrm{flakes} \mathrm{with}$ enhanced microwave absorption ability. Phys Chem Chem Phys 2017, 19: 9128-9136.

[37] Feng YR, Guo X, Gong HY, et al. Microwave absorption performance of PDCs-SiCN(Fe) ceramics with negative imaginary permeability. Ceram Int 2018, 44: 10420-10425.

Open Access This article is licensed under a Creative Commons Attribution 4.0 International License, which permits use, sharing, adaptation, distribution and reproduction in any medium or format, as long as you give appropriate credit to the original author(s) and the source, provide a link to the Creative Commons licence, and indicate if changes were made.

The images or other third party material in this article are included in the article's Creative Commons licence, unless indicated otherwise in a credit line to the material. If material is not included in the article's Creative Commons licence and your intended use is not permitted by statutory regulation or exceeds the permitted use, you will need to obtain permission directly from the copyright holder.

To view a copy of this licence, visit http://creativecommons.org/licenses/by/4.0/. 